\title{
METABOLIC SYNDROME IN FEMALE WORKERS FROM A TEXTILE MILL: EFFECT OF NOISE
}

\author{
SEEMA GUPTA ${ }^{1}$, SUNITA GULATI ${ }^{2}$, GAURAV GUPTA ${ }^{3 *}$
}

${ }^{1}$ Department of Physiology, Venkateshwara Institute of Medical Sciences, Gajraula, Uttar Pradesh, India. ${ }^{2}$ Department of Obstetrics \& Gynaecology, Venkateshwara Institute of Medical Sciences, Gajraula, Uttar Pradesh, India. ${ }^{3}$ Department of Biochemistry, Santosh Medical College \& Hospital, Santosh University, Ghaziabad, Uttar Pradesh, India. Email: gaurav.ac.in@gmail.com

Received: 27 October 2016, Revised and Accepted: 15 November 2016

\section{ABSTRACT}

Objective: Noise creates alteration in human health in both physical as well as psychological variations. Effect of noise on components of metabolic syndrome (MetS) has been discussed but not well established. The aim of this study was to investigate the MetS in female workers from textile mill.

Methods: A total of 65 female workers were recruited for the study from the high noise $(>70 \mathrm{~dB})$ area and low noise $(<40 \mathrm{~dB})$ area of a textile mill. Body mass index (BMI), blood pressure (BP), blood sugar (BS), and lipid profile were investigated of the female workers. BP was estimated by auscultatory method. BS was investigated by glucose oxidase-peroxidase (POD) method. Total cholesterol (TC), triglycerides (TG), high-density lipoprotein cholesterol (HDL-C), and low-density lipoprotein cholesterol (LDL-C) were investigated by cholesterol oxidase (CHOD)-POD method, GPOPAP method, CHOD-POD/phosphotungustate method, and friedewald formula, respectively.

Results: Significant outcomes were obtained in this study. BMI was significantly $(<0.01)$ higher in workers working in high noise area compared to low noise $(<40 \mathrm{~dB})$ area. Systolic BP and diastolic BP was also significantly $(<0.01)$ higher in high noise area. Fasting BS level was found to be significantly $(<0.01)$ lower in low noise area. In case of lipid profile significant $(<0.01)$ results were obtained except LDL-C. TC and TG were found to be related with noise since their concentration was higher in high noise area compared to low noise area. However, HDL-C was found to be lower in high noise area compared to low noise area.

Conclusion: Continuous exposure to occupational noise might be reason for developing cardiovascular disease depending on the degree of MetS in industrial workers. BP and BS seems to be better predictor of MetS in assessing cardiovascular risk.

Keywords: Occupational noise, Metabolic syndrome, Dyslipidemia.

(C) 2017 The Authors. Published by Innovare Academic Sciences Pvt Ltd. This is an open access article under the CC BY license (http://creativecommons. org/licenses/by/4. 0/) DOI: http://dx.doi.org/10.22159/ajpcr.2017.v10i2.15917

\section{INTRODUCTION}

Noise pollution is one of principal risk factors for affecting human health [1]. Noise pollution is exerted through the noise, developed from road traffic, loud speakers, crackers, mechanical or electronic instruments and occupational or industrial work [2]. Noise, an unwanted or unacceptable sound [3], which create physiological as well as psychological variations to the individuals [4]. Health related issues from occupational noise have been widely discussed. Apart from noiseinduced hearing loss, there are various other factors since noise creates disturbance, annoyance as mental strain and may decline the physical performance of a person [5]. Continuous exposure of noise enhances the stress, is directly proportional developing cardiovascular changes in the long-term and may be the prime cause of developing hypertension since blood pressure (BP) is adversely affected by noise [6]. Consistent increase in BP may lead to hypertension, which is an important factor of metabolic syndrome (MetS) [7]. MetS is a disorder, characterized by increased body mass index (BMI), dyslipidemia, consistent hypertension, and hyperglycemia [8]. Occupational noise creates alterations in other variables of MetS is not well established and still a matter of discussion $[9,10]$. By keeping in mind that view the aim of this study was to investigate the effect of noise on various components of MetS in female workers of the textile mill.

\section{MATERIALS AND METHODS}

\section{Materials}

This cross-sectional study was conducted in the Department of Physiology, Venkateshwara Institute of Medical Science, Gajraula, Uttar Pradesh, India. A total of 65 female textile workers were enrolled for the study, out of which 35 females were selected from working in high noise area $(>70 \mathrm{~dB})$ and rest 30 females were from low noise area $(<40 \mathrm{~dB})$ [11]. The level of noise in high noise area, as well as low noise area was measured by noise dosimeter at the textile mill. The age group criterion for this study population was $25-45$ years. All the female participants were sent to the Department of Obstetrics and Gynecology to rule out any female gyne problem. All the participants voluntarily participated in this study. The written consent was obtained from each participant. Fasting blood sample was collected from every participant. This study was ethically approved by the Institutional Ethical Committee.

\section{Exclusion criteria}

1. Previous history of cardiovascular disease

2. Known hypertensive and diabetes mellitus women

3. Women taking lipid-lowering drugs, antihypertensive drugs

4. Women having pregnancy or 2 years history of pregnancy

5. Working history in noise area $<2$ years

6. Irregular menstrual cycle and menopausal women

7. Workers having noise induced hearing loss

8. Workers having any renal disorder or any other related complications.

\section{Inclusion criteria}

Only female workers from a textile mill were recruited for the study on the basis of the noise level of their working area.

\section{Methods}

1. BMI: BMI was presented in $\mathrm{kg} / \mathrm{m}^{2}$ which was calculated by measuring the weight of an individual in kilogram (kg) which was divided by the square of the height of that individual in meter (m) [12]:

a. Height: Height of an individual was estimated by wall-mounted stadiometer without shoes or sleeper 
b. Weight: Weight of an individual was recorded by digital weighing machine without shoe or sleeper and the person having light clothes.

2. BP: BP was measured by means of sphygmomanometer using an auscultatory method [13]:

i. Systolic BP(SBP): SBP was the maximum pressure exerted during systole

ii. Diastolic BP (DBP): DBP was the minimum pressure exerted during diastole.

3. Blood sugar (BS): Fasting BS (FBS) and postprandial BS (PPBS) were calculated by glucose oxidase-peroxidase (GOD-POD) method [14].

4. Lipid profile [15]:

a. Total cholesterol (TC): TC was investigated by the cholesterol oxidase (CHOD)-POD method using the spectrophotometer

b. Triglycerides (TG): TG was measured by GPO-PAP method by also using spectrophotometer

c. High-density lipoprotein cholesterol (HDL-C): HDL-C was measured by CHOD-POD/Phosphotungstate method by spectrophotometer

d. Low-density lipoprotein cholesterol (LDL-C): LDL-C was calculated by friedewald formula:

$$
\text { LDL }=\text { TC-HDL- } \frac{T G}{5}
$$

e. Very low-density lipoprotein (VLDL) cholesterol - VLDL was also calculated by friedewald formula:

$$
\text { VLDL }=\frac{T G}{5}
$$

\section{Statistical analysis}

All the results were expressed in mean \pm standard deviation. An unpaired Student's t-test was performed in textile workers for comparison of various parameters between high noise area and low noise area. A $p<0.05$ was considered statistically significant. Statistical software IBM SPSS version 20.0 was used for statistical analysis.

\section{RESULTS}

There were significant findings obtained in this study. There was higher BMI observed in workers working in high noise area compared to low noise area. This difference was highly significant $(<0.01)$. There was increased concentration of FBS and PPBS in workers exposed to noise $>70 \mathrm{~dB}$ compared to those working in noise $<40 \mathrm{~dB}$ and this finding was highly significant $(<0.01)$ in FBS not in PPBS. In the case of BP there were higher levels of SBP and DBP observed in Group I compared to Group II. These levels were highly significant between the groups $(<0.01)$. In the case of lipid profile, there were significant results observed between the groups except for LDL-C. The workers having TG >350 mg/dl were excluded from the study for use of friedewald formula in LDL estimation. TC and TG were highly elevated in workers exposed to noise $>70 \mathrm{~dB}$ compared to workers from low noise area $<40 \mathrm{~dB}$ and the results were highly significant. While in HDL-C, the concentration was significantly lower in Group I compared to Group II. The mean concentration of LDL cholesterol and VLDL were increased in high noise area workers compared to low noise area workers and this level was significant in VLDL not in LDL-C (Table 1). In the high noise area, there were $42.9 \%$ females workers were having increased BMI. $40 \%$ with elevated BP, $25.7 \%$ with hyperglycemia and $31.4 \%$ female workers were found to be with dyslipidemia (Fig. 1). While in low noise area, 3.3\% with increased BMI, $23.3 \%$ with elevated BP, $10 \%$ with hyperglycemia and $23.3 \%$ were found to be with dyslipidemia (Fig. 2).

\section{DISCUSSION}

Occupational noise plays a great impact on the health of an individual. Prolonged exposure to occupational noise develops high BP and anxiety which might be responsible for developing MetS [16]. In this study, adverse changes were found in various parameters in female textile workers. BMI was found to be associated with occupational noise since there was higher BMI in high noise area $(>70 \mathrm{~dB})$ compared to low noise area $(<40 \mathrm{~dB})$. Dzhambov and Dimitrova supported
Table 1: Baseline parameters in female workers of textile mill

\begin{tabular}{lllll}
\hline S. No. & Parameters & $\begin{array}{l}\text { High noise } \\
\text { area }\end{array}$ & $\begin{array}{l}\text { Low noise } \\
\text { area }\end{array}$ & p value \\
\hline 1. & Age (years) & $39.71 \pm 2.87$ & $42.26 \pm 1.81$ & 0.00 \\
2. & BMI (kg/m²) & $24.98 \pm 3.45$ & $22.38 \pm 1.80$ & 0.00 \\
3. & FBS (mg/dl) & $90.65 \pm 16.36$ & $84.23 \pm 6.97$ & 0.04 \\
4. & PPBS (mg/dl) & $125.51 \pm 27.36$ & $119.13 \pm 11.17$ & 0.21 \\
5. & SBP (mmHg) & $129.37 \pm 17.30$ & $117.10 \pm 8.89$ & 0.00 \\
6. & DBP (mmHg) & $83.22 \pm 9.20$ & $77.23 \pm 7.07$ & 0.00 \\
7. & TC (mg/dl) & $177.97 \pm 19.59$ & $161.86 \pm 8.34$ & 0.00 \\
8. & TG (mg/dl) & $192.74 \pm 79.30$ & $131.96 \pm 15.62$ & 0.00 \\
9. & HDL-C (mg/dl) & $47.06 \pm 8.67$ & $50.60 \pm 4.63$ & 0.04 \\
10. & LDL-C (mg/dl) & $87.87 \pm 21.36$ & $84.78 \pm 8.67$ & 0.43 \\
11. & VLDL (mg/dl) & $38.57 \pm 15.81$ & $26.38 \pm 3.14$ & 0.00 \\
\hline
\end{tabular}

All the variables were expressed in mean \pm SD. $p<0.05$ was considered statistically significant. BMI: Body mass index, FBS: Fasting blood sugar, PPBS: Postprandial blood sugar, SBP: Systolic blood pressure, DBP: Diastolic blood pressure, TC: Total cholesterol, TG: Triglycerides, HDL-C: High-density lipoprotein cholesterol, LDL-C: Low-density lipoprotein cholesterol, VLDL: Very low-density lipoprotein, SD: Standard deviation

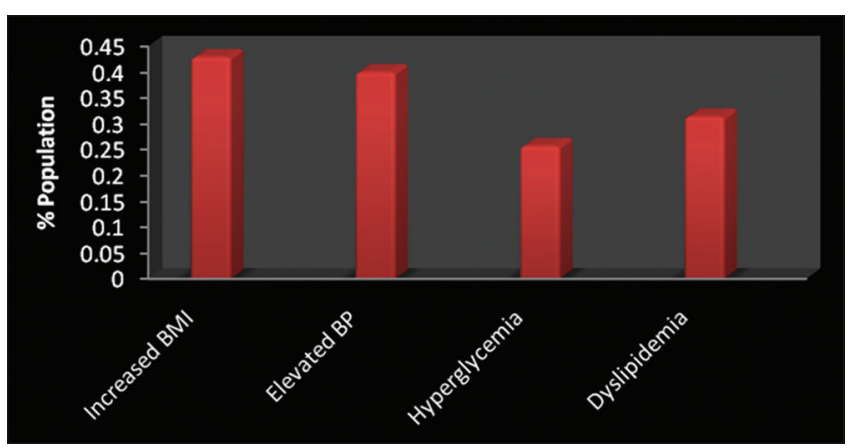

Fig. 1: The various parameters in high noise area

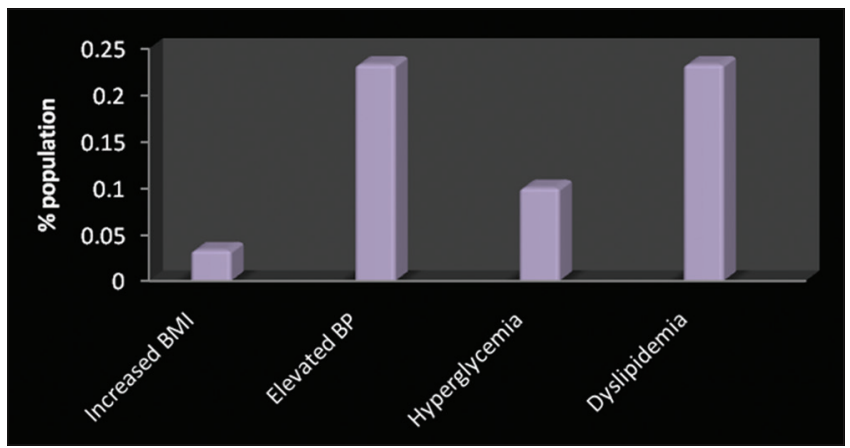

Fig. 2: The various parameters in low noise area

these findings by observing similar findings and reported a positive association between occupational noise and increased BMI [17]. Stress due to general high noise pollution and occupational noise can lead to increase BP, irritation, and sleep disturbance [18]. Similarly, a study from China reported the positive association between occupational noise and hypertension while studying on workers from automobile company [19]. Sympatheticotonia-induced endothelial lesion might be the possible mechanism for hypertension caused by noise [20]. There was increased a level of BP in workers working in high noise area when compared to workers working in low noise area. There were increased levels of SBP and DBP in high noise area $(>70 \mathrm{~dB})$. In support to this, Ismaila and Odusote concluded that workers should not be exposed to noise $>89 \mathrm{~dB}$ since they observed the increased level of SBP and DBP in noise area $>89 \mathrm{~dB}[21]$. Moreover, Fezil et al. also reported the higher levels of BP and blood glucose in noise area $>80 \mathrm{~dB}$ and concluded that occupational noise might be the possible contributic factors for developing hypertension and diabetes in industry workers [22]. There 
was increased a concentration of FBS and PPBS in noise area $>70 \mathrm{~dB}$ compared to noise area $<40 \mathrm{~dB}$ in this study. Recently, a study based on male mice supported our findings when they reported that continuous exposure to noise intensity $>90 \mathrm{~dB}$ can increase the BS level [23]. Similarly, a neonatal rats based study also concluded that noise has a significant hyperglycemic effect and leads to appropriate changes in serum lipids by increasing lipid profile [24]. In this study, there was significantly increased concentration of TC and TG in high noise area $(>70 \mathrm{~dB})$ when compared with workers working in low noise $(<40 \mathrm{~dB})$ area. A study from rubber manufacturing workers also supported these findings by observing the higher concentration of TC and TG in workers exposed to noise higher than the permissible limit compared to those working in exposed to noise lower than permissible limit. They further concluded that high intensity of noise is a risk factor for hypertension and further development of cardiovascular changes [25]. There was increase concentration of HDL and increased concentration of VLDL in high noise area workers. In support of our study, Mehrdad et al. also found that elevated concentration of TC, TG, and LDL along with decreased concentration of HDL in high noise area when compared to low noise area [26]. Furthermore, Li et al. also supported our study by concluding that significant effect of noise is related to increased prevalence of MetS [27]. Moreover, An 18-year follow-up study concluded that hypertension and BS, key components of MetS, are the best predictors for assessment of the risk of coronary heart disease due to continuous exposure to occupational noise in support to our study [28].

\section{CONCLUSION}

The outcome of this study reveals that there may be the increased prevalence of MetS in industrial workers due to adverse effect of noise. The female workers in high noise area were characterized with increased BMI, elevated BP, hyperglycemia and increased lipid profile which may give rise to cardiovascular diseases. Therefore, BMI, BP, BS, and lipid profile examination should be routinely performed along with auditory assessment of the workers. Since only limitation to this study was its sample size so study with large sample size should be conducted to establish this fact.

\section{REFERENCES}

1. Stansfeld SA, Matheson MP. Noise pollution: Non-auditory effects on health. Br Med Bull 2003;68:243-57.

2. Makopa Kenda I, Agoub M, Ahami AO. Noise effects on mental health: A review of literature. Sante Ment Que 2014:39(1):169-81.

3. Sridevi G, Sembulingam K, Sembulingam P, Ibrahim M, Srividya S. Evaluation of stress alleviating potential of pergularia daemia on certain immunological parameters. Int J Pharm Pharm Sci 2016;8(5):266-70.

4. van Dijk FJ. Non-auditory effects of noise in industry. II. A review of the literature. Int Arch Occup Environ Health 1986;58(4):325-32.

5. Passchier-Vermeer W, Passchier WF. Noise exposure and public health. Environ Health Perspect 2000;108 Suppl 1:123-31.

6. Chang TY, Jain RM, Wang CS, Chan CC. Effects of occupational noise exposure on blood pressure. J Occup Environ Med 2003;45(12):1289-96.

7. Alberti KG, Zimmet P, Shaw J. Metabolic syndrome - A new worldwide definition. A Consensus Statement from the International Diabetes Federation. Diabet Med 2006;23(5):469-80.

8. Londhe SS. A major health hazard: Metabolic syndrome. Int J Pharm Pharm Sci 2011;3(3):1-8
9. Melamed S, Harari G, Green MS. Type A behavior, tension, and ambulatory cardiovascular reactivity in workers exposed to noise stress. Psychosom Med 1993;55(2):185-92.

10. Sroczynski J, Wegiel A, Wieja A. Effect of vibration and noise on the fat balance in exposed workers. Med Pr 1979;30(1):49-54.

11. Martinez-Abrain A. Is the ' $n=30$ rule of thumb' of echological field studies reliable? A call for the greater attention to the variability in our data. Anim Biodiveres Conserv 2014;37(1):95-100.

12. World Health Organization. Available from: http://www.who.int/ mediacentre/factsheets/fs311/en/index.html. [Last accessed on 2016 Aug].

13. Sahu D, Bhaskaran M. Palpatory method of measuring diastolic blood pressure. J Anaesthesiol Clin Pharmacol 2010;26(4):528-30.

14. Basak A. Development of a rapid and inexpensive plasma glucose estimation by two-point kinetic method based on glucose oxidaseperoxidase enzymes. Indian J Clin Biochem 2007;22(1):156-60.

15. Rifai N, Warnick GR, Remaley AT. Lipids, lipoproteins, apolipoproteins, and other cardiovascular risk factors. In: Burtis CA, Ashwood ER, Bruns DE, editors. Teitz Fundamentals ofClinical Chemistry. Pennsylvania: Saunders An Imprint of Elsevier Inc; 2010. p. 422-4.

16. Gupta S, Ghatak C. Environmental noise assessment and its effect on human health in an urban area. Int J Environ Sci 2011;1(7):1954-64

17. Dzhambov AM, Dimitrova DD. Long-term self-reported exposure to occupational noise is associated with BMI-defined obesity in the US general population. Am J Ind Med 2016;59(11):1009-19.

18. van Kempen EE, Kruize H, Boshuizen HC, Ameling CB, Staatsen BA, de Hollander AE. The association between noise exposure and blood pressure and ischemic heart disease: A meta-analysis. Environ Health Perspect 2002;110(3):307-17.

19. Wang S, Qin Q, Liu L, Han L, Chen Y. A cross-sectional study on the effects of occupational noise exposure on hypertension or cardiovascular among workers from automobile manufacturing company of Chongqing, China. J Biomed Sci Eng 2013;6(12):1137-42.

20. Chang TY, Su TC, Lin SY, Jain RM, Chan CC. Effects of occupational noise exposure on 24-hour ambulatory vascular properties in male workers. Environ Health Perspect 2007;115(11):1660-4

21. Fezil M, Narmadha MP, Benson B. Influence of occupational noise on insulin, blood glucose, homocysteine, blood pressure and heart rate. Int J Pharm Clin Sci 2013;3(2):14-9.

22. Ismaila SO, Odusote A. Noise exposure as a factor in the increase of blood pressure of workers in a sack manufacturing industry. Beni Suef Univ J Basic Appl Sci 2014;3(2):116-21.

23. Taban ET, Mortazavi SB, Vosoughi S, Khavanin A. Investigating the effects of noise exposure on intensification of diabetes mellitus, serum glucose, cortisol level and body weight of the male mice. J Paramed Sci 2016;7(4):11-20.

24. Mirshekar MA, Arabmoazzen S, Parivar K, Sarkaki A. Effect of chronic noise stress on serum glucose and lipids and morphology of langerhans islets in neonatal rats. Zahedan J Res Med Sci 2015;17(10):e2188.

25. Attarchi M, Dehghan F, Safakhah F, Nojomi M, Mohammadi S. Effect of exposure to occupational noise and shift working on blood pressure in rubber manufacturing company workers. Ind Health 2012;50(3):205-13.

26. Mehrdad R, Bahabad AM, Moghaddam AN. Relationship between exposure to industrial noise and serum lipid profile. Acta Med Iran 2011;49(11):725-9.

27. Li X, Wang C, Fan H, Wang X, Zhang M, Jia C, et al. Association between joint of heat and noise and metabolic syndrome in steel workers. Wei Sheng Yan Jiu 2015;44(1):77-81.

28. Koskinen HL, Kauppinen T, Tenkanen L. Dual role of physical workload and occupational noise in the association of the metabolic syndrome with risk of coronary heart disease: Findings from the Helsinki Heart Study. Occup Environ Med 2011;68(9):666-73. 